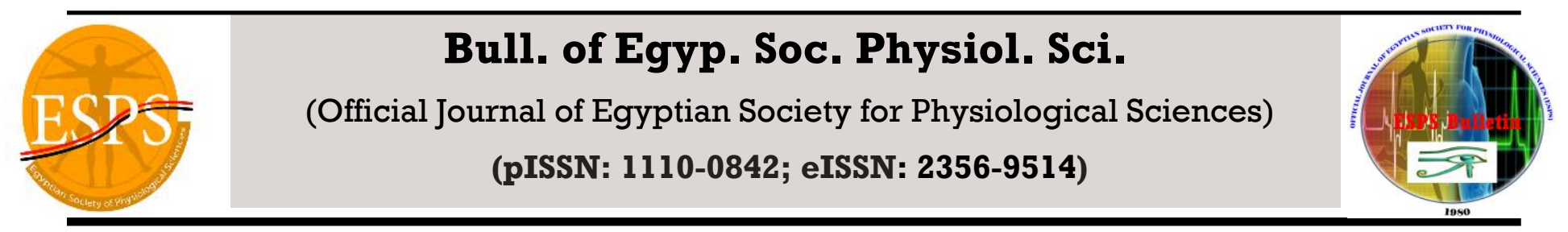

\title{
Effect of metformin and indole-3-carbinol on a rat model of Parkinson's disease induced by 6-hydroxydopamine
}

\author{
Hany M. Borg ${ }^{1}$, Ahmed M. Kabel ${ }^{2,3, *}$, Mona A. Abdel-Kareem ${ }^{4}$ \\ 1Department of Physiology, Faculty of Medicine, Kafrelsheikh University, Egypt \\ 2Pharmacology Department, Faculty of Medicine, Tanta University, Tanta, Egypt \\ 3Department of Clinical Pharmacy, College of Pharmacy, Taif University, Taif, Saudi Arabia \\ 4 Anatomy and Embryology Department, Faculty of Medicine, Kafrelsheikh University, Egypt
}

Received: 21 July 2019

Accepted: 16 August 2019

Available online: 1 Jan 2020

\section{Keywords}

- Metformin

- indole-3-carbinol

- 6-OHDA

- Parkinsonism

- Rats

\begin{abstract}
Parkinson's disease (PD) is a motor system disorder caused by factors that lead to depletion of dopamine from the dopaminergic neurons in the substantia nigra. Mechanisms of PD include mitochondrial dysfunction, oxidative stress and neuroinflammation. Metformin is an old antidiabetic drug that has recently been shown to offer protective effects against many types of cancer, cardiovascular and neurodegenerative diseases. Indole-3-carbinol (I3C) is a phytochemical derived from the cruciform vegetables. Recently, I3C was proven to have antioxidant, anti-inflammatory and neuroprotective properties. The aim of this work was to study the effect of metformin and/or I3C on 6-hydroxydopamine (6-OHDA)-induced PD in rats. Sixty male Wistar rats were divided into 6 equal groups: Control; 6-OHDA, metformin + 6-OHDA; I3C + 6-OHDA; carboxymethyl cellulose + 6-OHDA and metformin + I3C + 6-OHDA group. Striatal dopamine, tumor necrosis factor alpha (TNF- $\alpha$ ), interleukin-6 (IL-6), transforming growth factor beta1 (TGF- $\beta 1$ ), malondialdehyde (MDA), superoxide dismutase (SOD), glutathione reductase (GR), mitochondrial complex 1 activity, total swim score and catalepsy score were measured. The striatum was subjected to immunohistochemical examination. The combination between metformin and I3C induced significant increase in striatal SOD, GR, mitochondrial complex 1 activity and dopamine with significant decrease in striatal TNF- $\alpha$, IL-6, TGF- $\beta 1$, MDA and nuclear factor kappa-B expression with significant improvement in catalepsy and total swim scores better than the groups that received either I3C or metformin alone. So, metformin/I3C combination may represent a beneficial therapeutic modality for amelioration of 6-OHDAinduced PD in rats..
\end{abstract}

Corresponding author: Dr. Ahmed M. Kabel, El-Geish street, Faculty of Medicine, Tanta University, Department of Pharmacology, Tanta, Egypt; E-mail: ahmed.kabal@med.tanta.edu.eg; Tel.: +201102344533, +966564833526; Postal code: 31527 


\section{INTRODUCTION}

Parkinson's disease (PD) is the second most common neurodegenerative disorder worldwide affecting about $1 \%$ of the patients older than 60 years [1]. PD is usually precipitated by death of the dopaminergic neurons in the basal ganglia [2]. Up till now, the mechanisms underlying the pathogenesis of PD have not yet been completely elucidated. However, these molecular mechanisms were thought to include mitochondrial dysfunction, oxidative stress, neuroinflammation and affection of apoptosis [3].

In the past few decades, animal models of PD were used to explore the pathogenesis and find new therapeutic strategies for this neurodegenerative disease. Generally, these models are based on systemic or local administration of neutoxins that are able to produce most of the pathological and phenotypic features of PD [4]. These models include 1-methyl-4-phenyl-1,2,3,6tetrahydropyridine model, 6-hydroxydopamine (6OHDA) model, paraquat model, rotenone model and genetic models [5]. Intracerebral injection of 6-OHDA may induce mitochondrial dysfunction of dopaminergic neurons in the basal ganglia via inhibition of the activity of mitochondrial respiratory chain complex I and IV and reduction of the mitochondrial membrane potential [6]. Moreover, 6-OHDA undergoes metabolic degradation producing free radicals that cause lipid peroxidation and DNA oxidation resulting in oxidative stress and neuroinflammation [7]. Also, 6-OHDA may disrupt the balance between the excitatory and inhibitory neurotransmitters in the brain leading to precipitation of some of the characteristic features of PD [8].
Metformin is an euglycemic drug that was used over years for management of diabetes mellitus. It decreases intestinal absorption of glucose and increases its anaerobic oxidation. Moreover, metformin increases the sensitivity of insulin receptors and decreases glucagon release [9]. Recent reports suggest that metformin may have neuroprotective effects against many neurodegenerative disorders $[10,11]$. These effects may be attributed to the antioxidant and antiinflammatory properties of metformin together with its ability to restore mitochondrial functions and inhibit apoptosis [12].

Indole-3-carbinol (I3C) is one of the indole compounds that are found in cruciferous vegetables, such as broccoli, which is formed by enzymatic breakdown of glucosinolate glucobrassicin by myrosinase [13]. Several reports indicated that $\mathrm{I} 3 \mathrm{C}$ has potent antioxidant effects, possibly through decreased production of reactive oxygen species (ROS) and acting as free radical scavenger [14]. Also, I3C was proven to inhibit the inflammatory cascade at the gene expression level [15]. These properties together with the ability of I3C to decrease the expression of neuron specific enolase and increase monoamines levels in the brain may make $\mathrm{I} 3 \mathrm{C}$ to represent a promising hope for management of neurological disorders [16]. The aim of this work was to clarify whether metformin and/or I3C has an effect on 6-OHDA-induced PD in rats and to explore the possible mechanisms of this effect.

\section{Materials and Methods}

\subsection{Chemicals and drugs}

Metformin hydrochloride was obtained from SEDICO, Egypt. Carboxymethyl cellulose (CMC) was obtained from Sigma 
Pharmaceutical Company, Quesna, Egypt. 6OHDA, I3C and other chemicals were obtained from Sigma Chemical Co. (St. Louis, MO, USA). Metformin was freshly dissolved in distilled water. $\mathrm{I} 3 \mathrm{C}$ was suspended in $0.5 \% \mathrm{CMC}$ solution.

\subsection{Animals}

This study was performed on 60 male adult Wistar rats weighing about 150-200 grams. They were allowed to acclimatize for two weeks before starting the experiment. Rats were kept in a special room at a constant temperature of $25 \pm 3^{\circ} \mathrm{C}$ with relative humidity of $57 \pm 3 \%$ and were exposed to $12 \mathrm{~h}$ light/dark cycle. They were fed with standard diet and distilled water provided ad libitum. All the experiments were conducted according to the National Research Council's guidelines. This study was approved by the Research Ethics Committee of faculty of medicine, Tanta University, Egypt (Approval code 674/5/17). Animal handling was followed according to Helsinki declaration of animal ethics.

\subsection{Stereotaxic administration of 6-OHDA to the substantia nigra in rats}

Stereotaxic surgery was carried out according to Chan et al. [17]. Briefly, rats were anaesthetised with $75 \mathrm{mg} / \mathrm{kg}$ ketamine $/ 15 \mathrm{mg} / \mathrm{kg}$ xylazine and fixed on a stereotaxic frame (World Precision instruments, FL, US) with incisor bar adjusted at $5 \mathrm{~mm}$ above the interaural line. The skull plates were exposed after the scalp was incised. The needle of a microinjector was placed to the left substantia nigra. 8 micrograms of 6-OHDA in $4 \mu 11 \%$ ascorbic acid containing saline were administered to the left substantia nigra in a rate of $2 \mu \mathrm{l}$ in one minute. Buprenorphine was given subcutaneously to the operated rats in a dose of 0.5 $\mathrm{mg} / \mathrm{kg}$ during the first 96 hours after surgery. Signs of neurological and physiological abnormalities were observed when monitoring the postoperative health of rats.

\subsection{Groups}

Rats were divided randomly into six equal groups each of 10 rats as follows:

Group I: Control group received a single injection of $4 \mu 11 \%$ ascorbic acid containing saline in the left substantia nigra.

Group II: Received a single intranigral injection of 6-OHDA as described above.

Group III: Received metformin in a dose of 150 $\mathrm{mg} / \mathrm{kg} / \mathrm{day}$ orally for one week before and continued for 4 weeks after intranigral injection of 6-OHDA [18].

Group IV: Received I3C in a dose of $50 \mathrm{mg} / \mathrm{kg} /$ day orally for one week before and continued for 4 weeks after intranigral injection of 6-OHDA [16].

Group V: Received $0.5 \%$ CMC daily orally for one week before and continued for 4 weeks after intranigral injection of 6-OHDA.

Group VI: Received metformin concomitantly with I3C daily orally in the above-mentioned doses for one week before and continued for 4 weeks after intranigral injection of 6-OHDA.

\subsection{Assessment of the behavioral changes}

The development of PD was assessed at 28 days from injection of 6-OHDA, by occurrence of tremors, bradykinesia and rigidity in rats that was further quantified by catalepsy score. The first part was the grid test where the rat was hung by its paws on a vertical grid and the time needed for the rat to move its paws or any sort of first movement was recorded. The second part of the test was the bar test where the rat was placed with both forepaws on a bar and the time of removal of the paw was observed and recorded [19]. Also, the swimming 
ability test was carried out using tubes with $12 \mathrm{~cm}$ high water maintained at $25 \pm 3{ }^{\circ} \mathrm{C}$. Rats were placed in water and the swimming ability was recorded every minute for 10 minutes as follows: 3 continuous swimming, 2-swimming with occasional floating, 1-more floating with occasional swimming with hind limbs, and 0-hind part sinks with only the head floating [20].

At the end of the study, rats were killed by decapitation and the brain of each rat was immediately excised, washed with ice-cold saline and freezed at $-70{ }^{\circ} \mathrm{C}$. Then, the striata of the two hemispheres were isolated and weighed. One striatum was homogenized, centrifuged and the supernatant was used for estimation of the biochemical parameters and the other striatum was prepared for immunohistochemical examination of nuclear factor kappa B (NF- $\mathrm{kB})$ expression.

\subsection{Determination of striatal dopamine, superoxide dismutase (SOD), glutathione reductase (GR) and thiobarbituric acid derivatives (TBARS)}

Dopamine levels were measured in the striatal tissues using ELISA kits supplied by USCN Life Science Inc., Wuhan, China according to the manufacturer's instructions. Tissue SOD was measured according to Marklund and Marklund [21]. Tissue GR was assessed using kits supplied by Sigma Aldrich Co., USA, according to the instructions of the manufacturer. Tissue TBARS were measured using ELISA kits supplied by Cell Biolabs, Inc., San Diego, USA according to the manufacturer's instructions.

2.7. Determination of tissue transforming growth factor beta 1 (TGF- $\beta 1$ ), tumor necrosis factor alpha (TNF- $\alpha)$ and interleukin $6(I L-6)$
Tissue TGF- $\beta 1$ was determined using kits supplied by Uscn Life Science Inc. Wuhan, according to the manufacturer's instructions. Striatal TNF- $\alpha$ was assessed using rat TNF- $\alpha$ ELISA kits supplied by Ray Biotech, Inc. according to the manufacturer's instructions. Tissue IL-6 was measured using ELISA kits purchased from Sigma Aldrich Co. according to the instructions of the manufacturer.

\subsection{Determination of mitochondrial complex-I} activity

The nucleus caudatus putamen (NCP, striatum) and substantia nigra were dissected out from fresh frozen tissue sections of $1 \mathrm{~mm}$ thick. Then, tissues were sonicated in $0.1 \mathrm{M}$ potassium phosphate buffer $(\mathrm{pH} 7.8)$, centrifuged at $600 \times \mathrm{g}$ for 50 seconds and the supernatant was used for determination of mitochondrial complex-I activity according to Karuppagounder et al. [22].

\subsection{Determination of $N F-k B$ (p65) immunostaining} in the striatal tissues

Sections from the striatum were fixed in $10 \%$ neutral buffered formalin. Paraffin sections were prepared and immunostained with rat AntiNF- $\kappa B$ (p65) antibody (RayBiotech, USA) and the slides were examined under light microscope. The $\mathrm{NF}-\kappa \mathrm{B}$ was determined by detecting the activated subunit p65 in the examined tissues. Scoring of NF$\kappa \mathrm{B}$ (p65) immunostaining was performed according to the intensity of staining as $(+1)$ weak when nuclear staining is visible at (x200) magnification, $(+2)$ when visible at $(\mathrm{x} 100)$ magnification and $(+3)$ strong when visible at $(x 40)$ magnification [23]. The percentage of positive nuclear staining was calculated using IHC profiler tool in image $\mathbf{J}$ software $(1.49 \mathrm{v})$ National Institute of Health, USA [24]. 


\subsection{Statistical analysis}

The measured values were expressed as mean \pm standard error of mean (SEM). One way analysis of variance (ANOVA) was used to test significance of the difference among more than two arithmetic means followed by Scheffe test to test the difference between each two means. The significance of the results was considered at $\mathrm{p}$ values less than 0.05 .

\section{Results}

\subsection{Effect of different treatments on the behavioral tests}

Administration of 6-OHDA induced significant increase in catalepsy score of either grid test or bar test with significant decrease in the total swim score compared to the control group. Administration of metformin and/or I3C induced significant decrease in catalepsy score associated with significant increase in the total swim score compared to rats treated with 6-OHDA alone. Administration of $\mathrm{CMC}$ induced non-significant effect on catalepsy and total swim scores compared to rats treated with 6-OHDA alone. Concomitant administration of metformin and $\mathrm{I} 3 \mathrm{C}$ induced significant decrease in catalepsy score and significant increase in the total swim score compared to the use of each of these drugs alone (Table 1, Fig. 1). .

\subsection{Effect of different treatments on striatal dopamine}

Administration of 6-OHDA induced significant decrease in striatal dopamine compared to the control group. Administration of metformin and/or I3C induced significant increase in striatal dopamine compared to rats treated with 6-OHDA alone. Administration of CMC induced nonsignificant effect on striatal dopamine compared to rats treated with 6-OHDA alone. Concomitant administration of metformin and $\mathrm{I} 3 \mathrm{C}$ induced significant increase in striatal dopamine compared to the use of each of these drugs alone (Table 2).

\subsection{Effect of different treatments on oxidative} stress parameters

Administration of 6-OHDA induced significant increase in tissue TBARS with significant decrease in tissue SOD and GR compared to the control group. Administration of metformin and/or I3C induced significant decrease in tissue TBARS associated with significant increase in tissue SOD and GR compared to rats treated with 6-OHDA alone. Administration of $\mathrm{CMC}$ induced non-significant effect on the abovementioned parameters compared to rats treated with 6-OHDA alone. Concomitant administration of metformin and $\mathrm{I} 3 \mathrm{C}$ induced significant decrease in tissue TBARS and significant increase in tissue SOD and GR compared to the use of each of these drugs alone (Table 2). .

\subsection{Effect of different treatments on mitochondrial} complex I activity

Administration of 6-OHDA induced significant decrease in mitochondrial complex I activity compared to the control group. Administration of metformin and/or I3C induced significant increase in mitochondrial complex I activity compared to rats treated with 6-OHDA alone. Administration of $\mathrm{CMC}$ induced nonsignificant effect on mitochondrial complex I activity compared to rats treated with 6-OHDA alone. Concomitant administration of metformin and $\mathrm{I3C}$ induced significant increase in mitochondrial complex I activity compared to the use of each of these drugs alone (Fig. 2). 
Table 1: Catalepsy score in the different studied groups

\begin{tabular}{ccccccc}
\hline & Control & 6-OHDA & $\begin{array}{l}\text { 6-OHDA }+ \\
\text { Metformin }\end{array}$ & $\begin{array}{c}\text { 6-OHDA }+ \\
\text { I3C }\end{array}$ & $\begin{array}{c}\text { 6-OHDA + } \\
\text { CMC }\end{array}$ & $\begin{array}{c}\text { 6-OHDA + } \\
\text { Metformin }+ \text { I3C }\end{array}$ \\
\hline Grid test & $6.92 \pm 0.32$ & $61.2 \pm 3.01^{*}$ & $38.3 \pm 2.15^{\#}$ & $42.51 \pm 2.7^{\#}$ & $59.4 \pm 3.2$ & $26.61 \pm 1.73^{\# \$ \bullet}$ \\
\hline Bar test & $8.32 \pm 0.39$ & $55.32 \pm 2.66^{*}$ & $34.51 \pm 1.52^{\#}$ & $38.43 \pm 1.92^{\#}$ & $52.68 \pm 2.46$ & $24.57 \pm 0.98^{\# \bullet}$
\end{tabular}

Values were represented as mean \pm S.E.M.

* Significant compared to the control group (p-value less than 0.05); " Significant compared to 6-OHDA group (p-value less than 0.05);

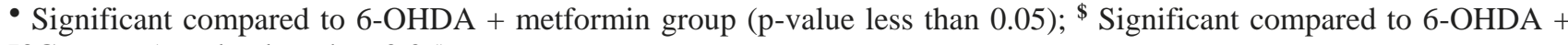
I3C group (p-value less than 0.05)

Table 2: Effect of different treatments on striatal dopamine, glutathione reductase (GR), superoxide dismutase (SOD) and thiobarbituric acid derivatives (TBARS) in the studied groups

\begin{tabular}{|c|c|c|c|c|c|c|}
\hline & Control & 6-OHDA & $\begin{array}{l}\text { 6-OHDA + } \\
\text { Metformin }\end{array}$ & $\begin{array}{c}\text { 6-OHDA + } \\
\text { I3C }\end{array}$ & $\begin{array}{c}\text { 6-OHDA + } \\
\text { CMC }\end{array}$ & $\begin{array}{c}\text { 6-OHDA + } \\
\text { Metformin }+\mathrm{I} 3 \mathrm{C}\end{array}$ \\
\hline $\begin{array}{l}\text { Striatal dopamine } \\
\text { (ng/mg tissue) }\end{array}$ & $10.21 \pm 0.42$ & $3.56 \pm 0.23^{*}$ & $6.16 \pm 0.32^{\#}$ & $5.79 \pm 0.26^{\#}$ & $3.72 \pm 0.24$ & $7.98 \pm 0.36^{\# \$ \bullet}$ \\
\hline $\begin{array}{l}\text { Striatal GR } \\
(\mathrm{U} / \mathrm{g} / \mathrm{min})\end{array}$ & $216.5 \pm 10.3$ & $125.68 \pm 6.6^{*}$ & $149.9 \pm 7.36^{\#}$ & $156.75 \pm 7.71^{\#}$ & $128.33 \pm 6.7$ & $186.84 \pm 8.8^{\# \$ \bullet}$ \\
\hline $\begin{array}{c}\text { Striatal SOD } \\
(\mathrm{U} / \mathrm{g} / \mathrm{min})\end{array}$ & $114.3 \pm 6.1$ & $63.64 \pm 3.4^{*}$ & $81.73 \pm 4.2^{\#}$ & $83.62 \pm 4.5^{\#}$ & $116.32 \pm 6.6$ & $98.82 \pm 5.7^{\# \$ \bullet}$ \\
\hline $\begin{array}{c}\text { Striatal TBARS } \\
(\mu \mathrm{M} / \mathrm{g} \text { tissue })\end{array}$ & $9.23 \pm 0.34$ & $62.32 \pm 3.3^{*}$ & $38.21 \pm 2.07^{\#}$ & $42.45 \pm 2.23^{\#}$ & $64.61 \pm 3.5$ & $25.57 \pm 1.24^{\# \$ \bullet}$ \\
\hline
\end{tabular}

Values were represented as mean \pm S.E.M.

* Significant compared to the control group (p-value less than 0.05); \# Significant compared to 6-OHDA group (pvalue less than 0.05);

- Significant compared to 6-OHDA + metformin group (p-value less than 0.05); ${ }^{\$}$ Significant compared to 6-OHDA + I3C group ( $\mathrm{p}$-value less than 0.05 )

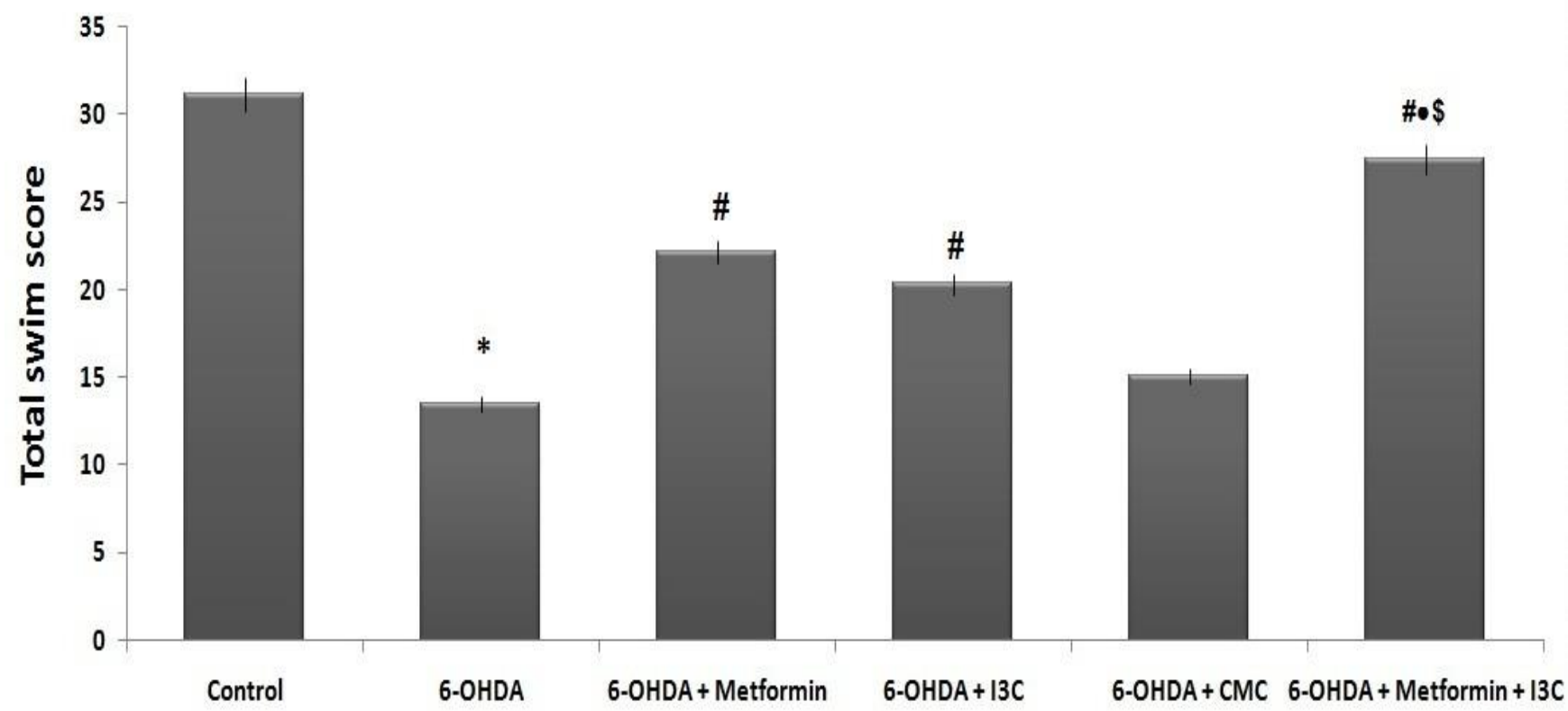

Figure 1: Effect of different treatments on the total swim score (Mean \pm SEM) * Significant compared to the control group (pvalue less than 0.05); \# Significant compared to 6-OHDA group (p-value less than 0.05); ${ }^{\bullet}$ Significant compared to 6-OHDA + metformin group (p-value less than 0.05); ${ }^{\$}$ Significant compared to 6-OHDA + I3C group (p-value less than 0.05). 


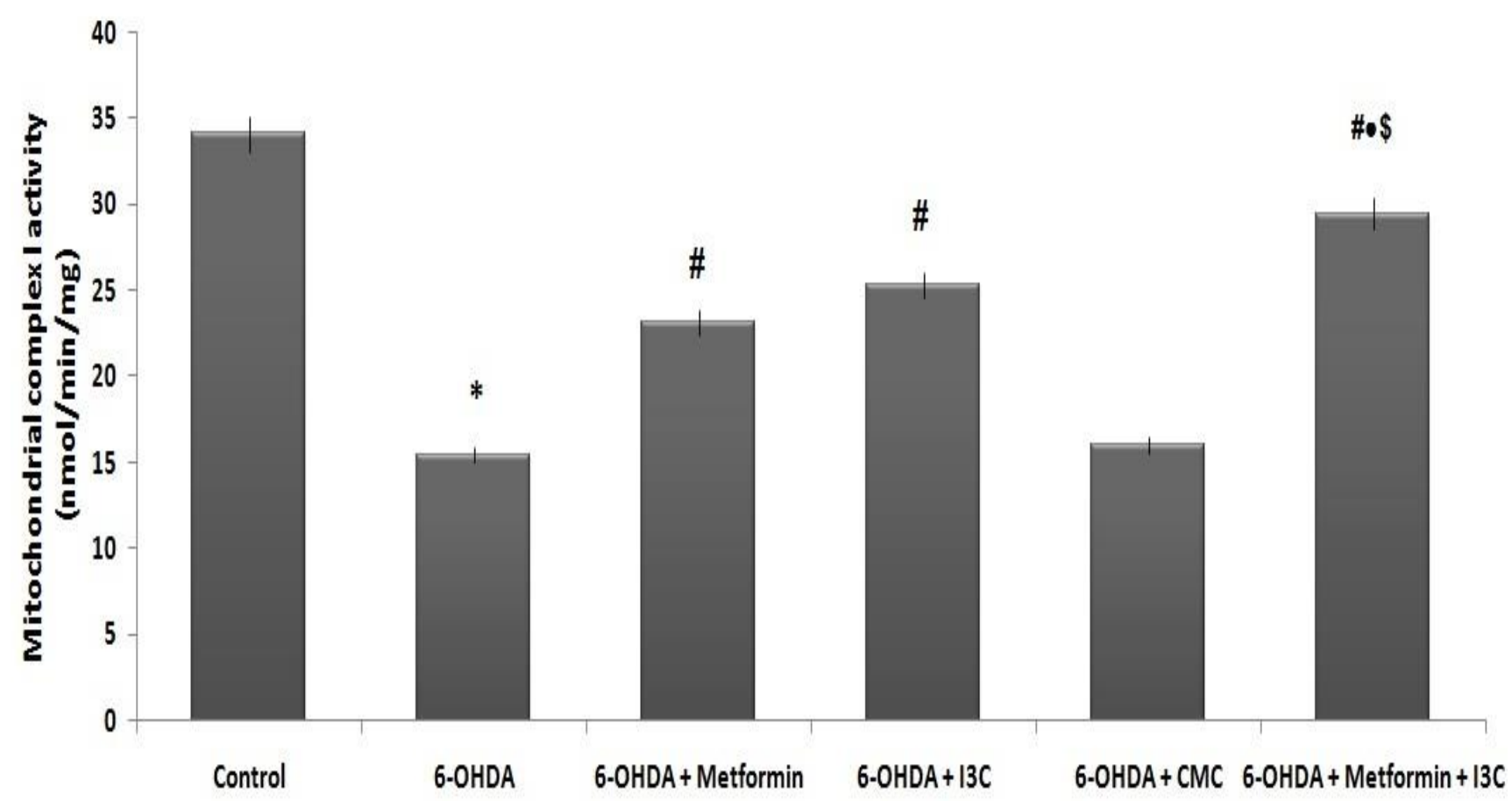

Figure 2: Effect of different treatments on the mitochondrial complex I activity (Mean \pm SEM)

* Significant compared to the control group (p-value less than 0.05); \# Significant compared to 6-OHDA group (p-value less than 0.05); • Significant compared to 6-OHDA + metformin group (p-value less than 0.05 ); ${ }^{\$}$ Significant compared to 6-OHDA + I3C group (p-value less than 0.05 ).

\subsection{Effect of different treatments on striatal TGF-}

$\beta 1, T N F-\alpha$ and $I L-6$

Administration of 6-OHDA induced significant increase in striatal TGF- $\beta 1$, TNF- $\alpha$ and IL-6 levels compared to the control group. Administration of metformin and/or I3C induced significant decrease in striatal TGF- $\beta 1$, TNF- $\alpha$ and IL-6 levels compared to rats treated with 6-OHDA alone. Administration of $\mathrm{CMC}$ induced nonsignificant effect on the above-mentioned parameters compared to rats treated with 6-OHDA alone. Concomitant administration of metformin and $\mathrm{I} 3 \mathrm{C}$ induced significant decrease in striatal TGF- $\beta 1$, TNF- $\alpha$ and IL- 6 levels compared to the use of each of these drugs alone (Table 3).

\subsection{Effect of different treatments on NF-kB (p65)}

immunostaining

6-OHDA administration induced significant increase in tissue NF-kB (p65) immunostaining compared to the control group. Administration of metformin and/or I3C induced significant decrease in tissue NF-kB (p65) immunostaining compared to rats treated with 6OHDA alone. Administration of CMC induced non-significant effect on tissue NF-kB (p65) immunostaining compared to rats treated with 6OHDA alone. Concomitant administration of metformin and I3C induced significant decrease in tissue NF-kB (p65) immunostaining compared to the use of each of these drugs alone (Fig. 3,4). 
Table 3: Effect of different treatments on striatal tumor necrosis factor alpha (TNF- $\alpha$ ), interleukin-6 (IL6) and transforming growth factor beta 1 (TGF-ß1) in the studied groups

\begin{tabular}{|c|c|c|c|c|c|c|}
\hline & Control & 6-OHDA & $\begin{array}{l}\text { 6-OHDA + } \\
\text { Metformin }\end{array}$ & $\begin{array}{c}\text { 6-OHDA + } \\
\text { I3C }\end{array}$ & $\begin{array}{c}\text { 6-OHDA + } \\
\text { CMC }\end{array}$ & $\begin{array}{c}\text { 6-OHDA + } \\
\text { Metformin } \\
+\mathrm{I} 3 \mathrm{C}\end{array}$ \\
\hline $\begin{array}{r}\text { Tissue TNF- } \alpha \\
\text { (pg/mg protein) }\end{array}$ & $43.7 \pm 2.8$ & $451.6 \pm 22.3^{*}$ & $316.7 \pm 18.3^{\#}$ & $327.3 \pm 17.9^{\#}$ & $444.8 \pm 21.5$ & $\begin{array}{c}232.6 \pm 12.8 \\
\# \bullet \bullet\end{array}$ \\
\hline $\begin{array}{c}\text { Tissue IL-6 } \\
\text { (pg/ mg protein) }\end{array}$ & $124.2 \pm 5.6$ & $433.4 \pm 21.4^{*}$ & $\underset{\#}{311.4 \pm 15.63}$ & $\begin{array}{c}342.3 \pm 16.3 \\
\#\end{array}$ & $439.8 \pm 22.3$ & $\begin{array}{c}224.6 \pm 13.4 \\
\# \$ \bullet\end{array}$ \\
\hline $\begin{array}{l}\text { Tissue TGF- } \beta 1 \\
\text { (pg/mg protein) }\end{array}$ & $22.16 \pm 1.33$ & $94.3 \pm 5.15^{*}$ & $67.42 \pm 3.53^{\#}$ & $72.81 \pm 3.66^{\#}$ & $91.63 \pm 4.64$ & $\begin{array}{c}44.23 \pm 2.38 \\
\text { \#\$ }\end{array}$ \\
\hline
\end{tabular}

Values were represented as mean \pm S.E.M.

* Significant compared to the control group (p-value less than 0.05); ${ }^{*}$ Significant compared to 6-OHDA group (p-value less than 0.05);

- Significant compared to 6-OHDA + metformin group (p-value less than 0.05); ${ }^{\$}$ Significant compared to 6-OHDA + I3C group (p-value less than 0.05)

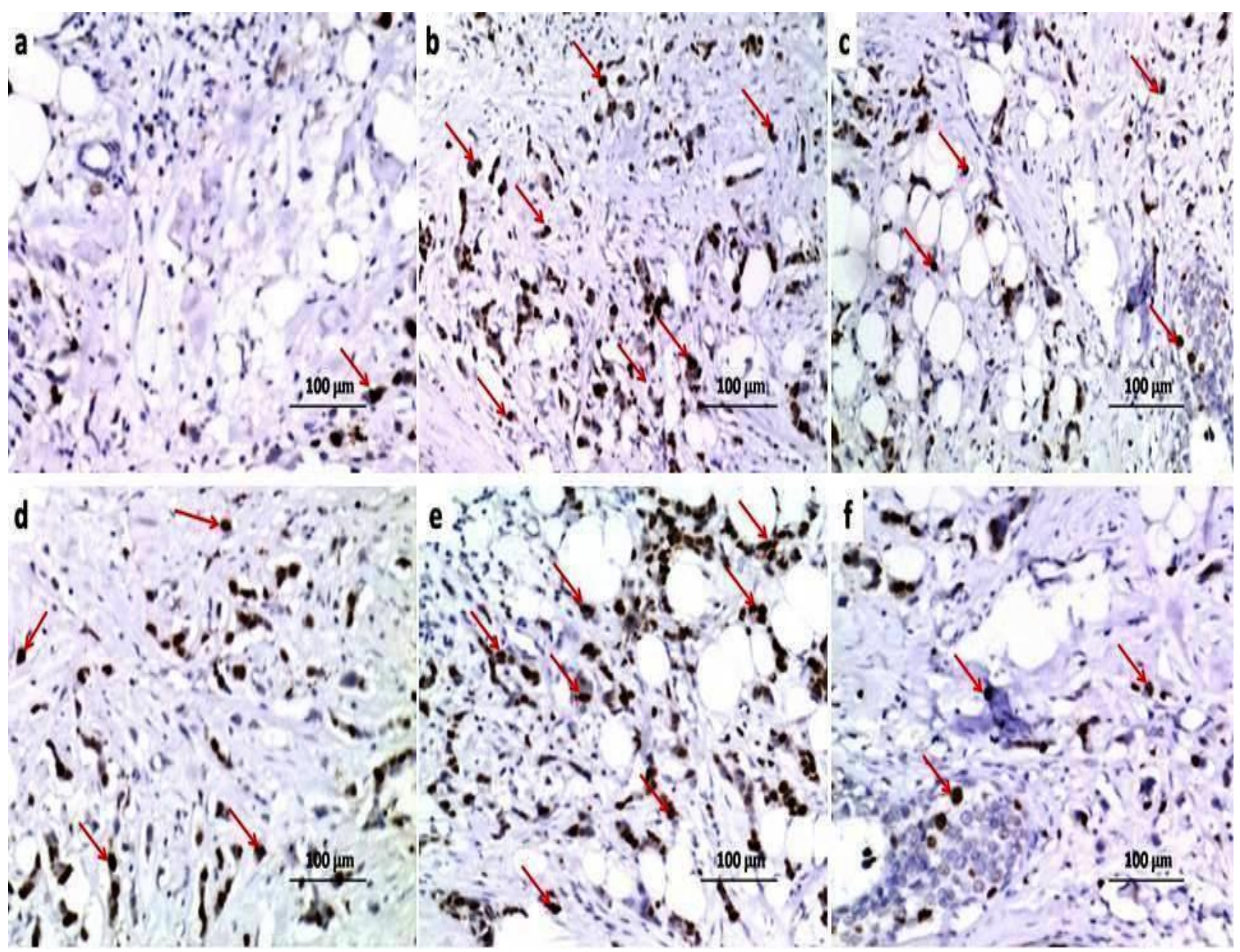

Figure 3: Immunohistochemical staining of NF- $\mathrm{B}(\mathrm{p} 65)(\mathrm{x} 400)$ in the brain tissues of a) control group showing minimal positive

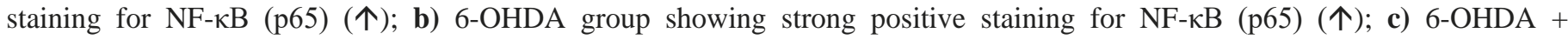
Metformin group showing moderate positive staining for NF- $\kappa \mathrm{B}(\mathrm{p} 65)(\uparrow)$; d) 6-OHDA + I3C group showing moderate positive

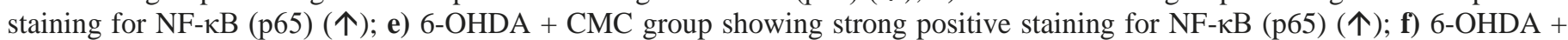
Metformin + I3C group showing weak positive staining for NF- $\mathrm{B}$ (p65) (个). 


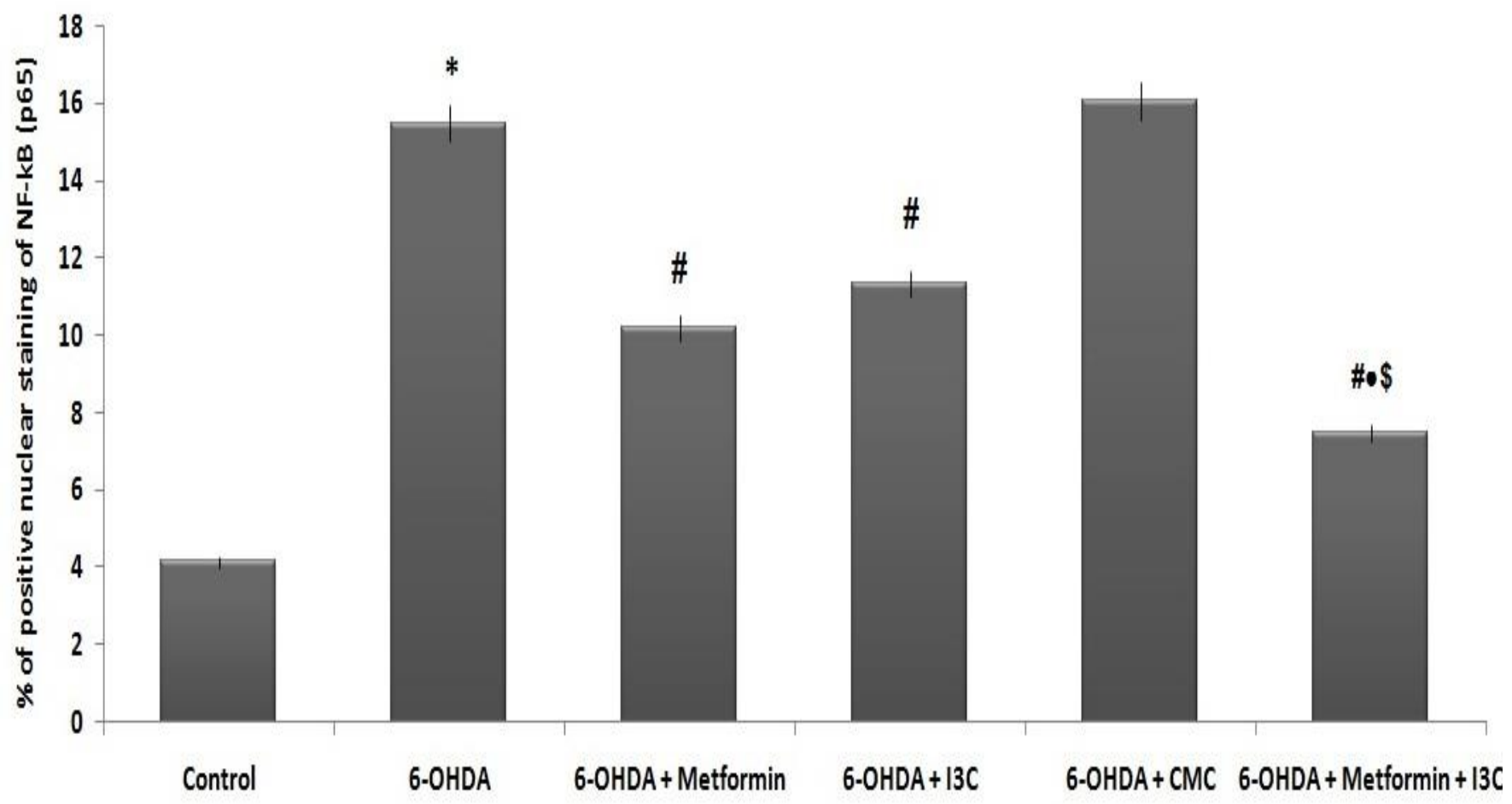

Figure 4: Percentage of positive nuclear staining of NF-kB (p65) (Mean \pm SEM)* Significant compared to the control group (pvalue less than 0.05); \# Significant compared to 6-OHDA group (p-value less than 0.05); • Significant compared to 6-OHDA + Metformin group (p-value less than 0.05); ${ }^{\$}$ Significant compared to 6-OHDA + I3C group (p-value less than 0.05).

\section{Discussion}

Parkinson's disease represents one of the most common age-related neurodegenerative disorders, characterized by progressive loss of substantia nigra pars compacta dopamine neurons with consequent decrease in the neurotransmitter dopamine [25]. The exact molecular mechanisms that underlie the pathogenesis of PD are still not yet well understood. However, induction of oxidative stress, increased formation of the proinflammatory cytokines, mitochondrial dysfunction and induction of apoptosis are suggested as precipitating factors for PD [26].

In the present study, 6-OHDA injection induced significant decrease in the striatal dopamine and total swim score associated with significant increase in the catalepsy score compared to the control group. This was in the same line with Beppe et al. [27] and Massari et al. [28] who reported that 6-OHDA induces loss of the dopaminergic neurons in the substantia nigra leading to decreased striatal dopamine. Zeng et al. [5] suggested that the alteration of the behavioral tests induced by 6-OHDA can be attributed to disruption of the balance between the glutamatergic and GABAergic activities in the brain. These changes were ameliorated in the present study with administration of metformin which was in agreement with Katila et al. [29] and Lu et al. [30] who reported that metformin prevents dopaminergic neuron death in PD via autophagy and clearance of mitochondrial ROS. Also, they stated that metformin decreases alpha-synuclein phosphorylation and upregulates neurotrophic factor which may ameliorate the behavioral changes 
frequently encountered in PD. Also, I3C in the present study had the ability to increase striatal dopamine and restore the normal response to the behavioral tests. This was explained by El-Naga et al. [16] by the ability of I3C to inhibit apoptosis and improve the vitality of dopaminergic neurons which will restore dopamine levels in the brain and improve the results of the behavioral tests.

Induction of oxidative stress appears to be the main factor incriminated in the pathogenesis of PD. Injection of 6-OHDA in the present study induced significant increase in striatal TBARS and significant decrease in the activities of the antioxidant enzymes compared to the control group. This was in agreement with Latchoumycandane et al. [31] who reported that 6OHDA increases generation of ROS which in turn suppress the activities of the antioxidant enzymes at the gene expression level. Also, they found that 6OHDA induced proteolytic cleavage and activation of protein kinase $\mathrm{C}$ delta $(\mathrm{PKC} \delta)$ which will promote oxidative stress in the dopaminergic neurons. Metformin in the present study was able to ameliorate oxidative stress which was in the same line with Patil et al. [32] who stated that long-term treatment with metformin resulted in significant improvement of the antioxidant enzymes activity in rodent model of PD. Also, I3C in the present study decreased tissue TBARS and increased the activity of the antioxidant enzymes. This was in agreement with El-Naga et al. [16] who reported that I3C has potent antioxidant effects that can be beneficial in various neurological disorders. These effects might be attributed to reduction of inducible nitric oxide synthase expression and inhibition of the generation of ROS in the brain tissues.
$\mathrm{NF}-\kappa \mathrm{B}$ is considered to be the "master switch" of the inflammatory cascade that is frequently encountered in PD [33]. NF- $\kappa B$ was proven to regulate the genes that regulate the expression of the proinflammatory cytokines and cell adhesion molecules. Also, the cross talk between NF- $\kappa B$ and TGF- $\beta 1$ expression leads to increased generation of TNF- $\alpha$, IL- 6 and ROS in the substantia nigra which in turn leads to massive degeneration of the dopaminergic neurons [34]. Also, it was proven that overexpression of TGF- $\beta 1$ in the nigrostriatal system increases the dopaminergic deficit of PD and aggravates the parkinsonian state [35]. This was in agreement with the results of the present study where injection of 6OHDA induced significant increase in striatal NF$\kappa \mathrm{B}$, TGF- $\beta 1$, TNF- $\alpha$ and IL- 6 compared to the control group.

In the present study, metformin significantly decreased tissue levels of $\mathrm{NF}-\kappa \mathrm{B}$, TGF- $\beta 1$, TNF- $\alpha$ and IL- 6 compared to the untreated 6-OHDA group. This was in agreement with Tayara et al. [18] and Patil et al. [32] who reported that metformin has widespread anti-inflammatory effects which may be related to inhibition of TGF$\beta 1$ expression and modulation of the activity of MAP kinase. Also, I3C in the present study was able to decrease the expression of NF- $\mathrm{kB}, \mathrm{TGF}-\beta 1$ and the proinflammatory cytokines which was in the same line with Jiang et al. [36] who attributed the anti-inflammatory effects of I3C to inhibition of cyclooxygenase-2 and lipoxygenase expression, immune cells infiltration and the production of the pro-inflammatory cytokines.

Mitochondrial dysfunction was reported to play a vital role in the pathophysiology of PD. Defects in the electron transport chain, 
mutations in the mitochondrial DNA, disruption of the mitochondrial dynamics and mutation of the proteins associated with mitochondria were found to be prominent features of PD [37]. This was proven in the present study where 6-OHDA injection induced significant decrease in mitochondrial complex I activity compared to the control group. This was ameliorated in our study with administration of metformin and/or I3C which supported the hypothesis that these agents can ameliorate the mitochondrial abnormalities frequently encountered in PD, possibly through increasing the activities of mitochondrial complexes I and IV and reversing tumor necrosis factor type 1 receptor mutation-associated alterations in mitochondrial functions [38,39].

In the present study, the combination between metformin and $\mathrm{I} 3 \mathrm{C}$ induced significant increase in striatal antioxidant enzymes, mitochondrial complex 1 activity and dopamine with significant decrease in striatal proinflammatory cytokines, TGF- $\beta 1$, MDA and $N F-\kappa B$ expression with significant improvement in catalepsy and total swim scores better than the groups that received either I3C or metformin alone. This might be due to the combined antioxidant and anti-inflammatory properties of both agents together with their ability to restore dopamine levels and mitochondrial functions in the brain tissues. It was reported that P-glycoprotein mediated efflux limits the transport of the antiparkinsonian drugs through the blood brain barrier [40]. Being an effective inhibitor of P-glycoprotein, I3C may decrease efflux of metformin and so may potentiate its anti-parkinsonian effects [41].

\section{Conclusion}

Metformin/I3C combination may represent a beneficial therapeutic modality for amelioration of 6-OHDA-induced PD in rats. This may be due to their antioxidant and antiinflammatory properties together with their abilities to restore mitochondrial functions and the ability of I3C to inhibit P-glycoprotein mediated efflux of metformin outside the brain tissues. Further studies are needed to explore the exact molecular mechanisms that underlie these effects.

\section{Limitations of the study}

The small sample size and the limited financial resources were the main limitations of this study.

\section{Conflict of interest}

The authors had no conflict of interest to declare

\section{References}

[1] DeMaagd G, Philip A. Parkinson's Disease and Its Management: Part 1: Disease Entity, Risk Factors, Pathophysiology, Clinical Presentation, and Diagnosis. PT 2015; 40(8): 504-532.

[2] Rizek P, Kumar N, Jog MS. An update on the diagnosis and treatment of Parkinson disease. CMAJ 2016;188(16):1157-1165.

[3] Fung VS. New and emerging treatments for Parkinson disease. Med J Aust 2015; 202(6):283284.

[4] Blandini F, Armentero MT. Animal models of Parkinson's disease. FEBS J 2012; 279(7): 11561166.

[5] Zeng XS, Geng WS, Jia JJ. NeurotoxinInduced Animal Models of Parkinson Disease: Pathogenic Mechanism and Assessment. ASN Neuro 2018;10:1759091418777438.

[6] Mercanti G1, Bazzu G, Giusti P. A 6hydroxydopamine in vivo model of Parkinson's disease. Methods Mol Biol 2012; 846: 355-364. 
[7] Hernandez-Baltazar

D, Zavala-Flores

LM, Villanueva-Olivo A. The 6-hydroxydopamine model and parkinsonian pathophysiology: Novel findings in an older model. Neurologia 2017; 32(8): 533-539.

[8] Maiti P, Manna J, Dunbar GL. Current understanding of the molecular mechanisms in Parkinson's disease: Targets for potential treatments. Transl Neurodegener 2017; 6: 28.

[9] Wang YW, He SJ, Feng X, et al. Metformin: a review of its potential indications. Drug Des Devel Ther. 2017;11:2421-2429.

[10] Markowicz-Piasecka M, Sikora J, Szydłowska A, Skupień A, Mikiciuk-Olasik E, Huttunen KM. Metformin - a Future Therapy for Neurodegenerative Diseases : Theme: Drug Discovery, Development and Delivery in Alzheimer's Disease Guest Editor: Davide Brambilla. Pharm Res 2017;34(12):2614-2627.

[11] Sanchis A, García-Gimeno MA, CañadaMartínez AJ, et al. Metformin treatment reduces motor and neuropsychiatric phenotypes in the zQ175 mouse model of Huntington disease. Exp Mol Med 2019;51(6):65.

[12] Bayliss JA, Lemus MB, Santos VV, et al. Metformin Prevents Nigrostriatal Dopamine Degeneration Independent of AMPK Activation in Dopamine Neurons. PLoS One 2016; 11(7): e0159381.

[13] Jeong JH, Kim JJ, Bak DH, Yu KS, Lee JH, Lee NS, Jeong YG, Kim DK, Kim DK, Han

SY. Protective Effects of Indole-3-Carbinol-Loaded Poly(lactic-co-glycolic acid) Nanoparticles Against Glutamate-Induced Neurotoxicity. J Nanosci Nanotechnol. 2015;15(10):7922-7928.

[14] Adwas AA, Elkhoely AA, Kabel AM, AbdelRahman MN, Eissa AA. Anti-cancer and cardioprotective effects of indol-3-carbinol in doxorubicin-treated mice. J Infect Chemother 2016; 22(1): 36-43.

[15] Kim JK, Park SU. Current results on the biological and pharmacological activities of Indole3-carbinol. EXCLI J 2018;17:181-185.

[16] El-Naga RN, Ahmed HI, Abd Al Haleem EN. Effects of indole-3-carbinol on clonidineinduced neurotoxicity in rats: Impact on oxidative stress, inflammation, apoptosis and monoamine levels. Neurotoxicology 2014;44:48-57.

[17] Chan HH, Kumar S, Zhuo L. Neuroprotective and behavioural assessments of an imidazolium compound (DBZIM) in a rat model of Parkinson's disease induced by 6-OHDA. Eur J Pharmacol 2013; 715(1-3):405-413.

[18] Tayara K, Espinosa-Oliva AM, GarcíaDomínguez I, et al. Divergent Effects of Metformin on an Inflammatory Model of Parkinson's Disease. Front Cell Neurosci 2018;12:440.

[19] Kabel AM, Omar MS, Alhadhrami A, Alharthi SS, Alrobaian MM. Linagliptin potentiates the effect of 1-dopa on the behavioural, biochemical and immunohistochemical changes in experimentally-induced Parkinsonism: Role of tolllike receptor 4 , TGF- $\beta 1$, NF- $\mathrm{BB}$ and glucagon-like peptide 1. Physiol Behav 2018;188:108-118.

[20] Haobam R, Sindhu KM, Chandra G, Mohanakumar KP. Swim-test as a function of motor impairment in MPTP model of Parkinson's disease: A comparative study in two mouse strains. Behav Brain Res 2005; 163: 159-167.

[21] Marklund S, Marklund G. Involvement of the superoxide anion radical in the autooxidation of pyrogallol and convenient assay for superoxide dismutase. Eur J Biochem 1974; 47: 469e74. 
[22] Karuppagounder SS, Madathil SK, Pandey

M, Haobam R, Rajamma U, Mohanakumar KP. Quercetin up-regulates mitochondrial complex-I activity to protect against programmed cell death in rotenone model of Parkinson's disease in rats. Neurosci 2013; 236: 136-148.

[23] Meteoglu I, Erdogdu I, Meydan N, Erkus M, Barutca S. NF-KappaB expression correlates with apoptosis and angiogenesis in clear cell renal cell carcinoma tissues. J Exp Clin Cancer Res 2008; 27: 53.

[24] Varghese F, Bukhari AB, Malhotra R, De A. IHC Profiler: an open source plugin for the quantitative evaluation and automated scoring of immunohistochemistry images of human tissue sample. PLoS One 2014; 9: e96801.

[25] Johnson IP. Age-related neurodegenerative disease research needs aging models. Front Aging Neurosci 2015;7:168.

[26] Blesa J, Trigo-Damas I, Quiroga-Varela A, Jackson-Lewis VR. Oxidative stress and Parkinson's disease. Front Neuroanat 2015;9:91.

[27] Beppe GJ, Dongmo AB, Foyet HS, Dimo T, Mihasan M, Hritcu L. The aqueous extract of Albizia adianthifolia leaves attenuates 6hydroxydopamine-induced anxiety, depression and oxidative stress in rat amygdala. BMC Complement Altern Med 2015;15:374.

[28] Massari CM, López-Cano M, Núñez F, Fernández-Dueñas V, Tasca CI, Ciruela F. Antiparkinsonian Efficacy of Guanosine in Rodent Models of Movement Disorder. Front Pharmacol 2017; 8:700.

[29] Katila N, Bhurtel S, Shadfar S, Srivastav S, Neupane S, Ojha U, et al. . Metformin lowers alpha-synuclein phosphorylation and upregulates neurotrophic factor in the MPTP mouse model of
Parkinson's

disease. Neuropharmacol

$2017 ; 125: 396-407$.

[30] Lu M, Su C, Qiao C, Bian Y, Ding J, Hu G. Metformin prevents dopaminergic neuron death in MPTP/P-induced mouse model of parkinson's disease via autophagy and mitochondrial ROS clearance. Int J Neuropsychopharmacol 2016;19: pyw047.

[31] Latchoumycandane C, Anantharam V, Jin H, Kanthasamy A, Kanthasamy A. Dopaminergic neurotoxicant 6-OHDA induces oxidative damage through proteolytic activation of $\mathrm{PKC} \delta$ in cell culture and animal models of Parkinson's disease. Toxicol Appl Pharmacol 2011; 256(3): 314-323.

[32] Patil SP, Jain PD, Ghumatkar PJ, Tambe R, Sathaye S. Neuroprotective effect of metformin in MPTP-induced Parkinson's disease in mice. Neuroscience 2014; 277:747-754.

[33] Pires BRB, Silva RCMC, Ferreira GM, Abdelhay E. NF-kappaB: Two Sides of the Same Coin. Genes (Basel) 2018; 9(1):24.

[34] Rocha NP, de Miranda AS, Teixeira AL. Insights into Neuroinflammation in Parkinson's Disease: From Biomarkers to Anti-Inflammatory Based Therapies. Biomed Res Int 2015; 2015: 628192.

[35] Sánchez-Capelo A, Colin P, Guibert B, Biguet NF, Mallet J. Transforming growth factor beta1 overexpression in the nigrostriatal system increases the dopaminergic deficit of MPTP mice. Mol Cell Neurosci 2003; 23: 614-625.

[36] Jiang J, Kang TB, Shim W, Oh NH, Kim TJ, Lee KH. Indole-3-carbinol inhibits LPSinduced inflammatory response by blocking TRIFdependent signaling pathway in macrophages. Food Chem Toxicol 2013; 57: 256-261. 
[37] Park JS, Davis RL, Sue CM. Mitochondrial

Dysfunction in Parkinson's Disease: New

Mechanistic Insights and Therapeutic

Perspectives. Curr Neurol Neurosci Rep

2018;18(5):21.

[38] Chen DZ, Qi M, Auborn KJ, Carter TH.

Indole-3-carbinol and diindolylmethane induce apoptosis of human cervical cancer cells and in murine HPV16-transgenic preneoplastic cervical epithelium. J Nutr 2001; 131(12):3294-3302.

[39] Rai SN, Singh SS, Birla H, et al. Commentary: Metformin reverses TRAP1 mutation-associated alterations in mitochondrial function in Parkinson's disease. Front Aging Neurosci 2018; 10: 221.

[40] Liu Q, Hou J, Chen X, et al. P-glycoprotein mediated efflux limits the transport of the novel anti-Parkinson's disease candidate drug FLZ across the physiological and PD pathological in vitro BBB models. PLoS One 2014; 9(7): e102442.

[41] Arora A, Shukla Y. Modulation of vincaalkaloid induced P-glycoprotein expression by indole-3-carbinol. Cancer Lett 2003; 189(2): 167173. 